\title{
Loss of Historical Phonetic Contrast Across the Lifespan: Articulatory, Lexical, and Social Effects on Sound Change in Swabian ${ }^{1}$
}

\author{
Karen V. Beaman and Fabian Tomaschek, University of Tübingen
}

\section{Abstract}

This chapter explores the extent to which phonetic environment, lexical frequency, and social factors interact and incite or impede sound change over the lifespan of the individual. The corpus consists of sociolinguistic interviews with 20 panel speakers of Swabian, an Alemannic dialect spoken in southwestern Germany, from two different communities, Stuttgart and Schwäbisch Gmünd, first recorded in 1982 and again in 2017. We investigate the modern standard German diphthong [ai] which evolved from two different Middle High German (MHG) phonemes, /i:/ and /ei/. We use generalised additive mixed-effect models to investigate to what extent F1/F2 trajectories in the vowel space differ in lemmata originating from the two MHG phonemes based on the Total Euclidean Distance Squared (TEDS). In addition to voicing effects, we find that an interaction between community, lexical frequency, and indexicalities of Swabian identity affects the degree to which the two diphthongs are merging, or at least becoming more similar to one another, within the lifespan of one generation. By analysing intra-speaker trajectories, we show how sound change is governed by the intricate interplay between structural factors and individual speaker notions of language ideology, social meaning, and dialect identity.

\section{Introduction}

Since Labov's seminal work on sound change in Martha's Vineyard (Labov 1962) and New York City (Labov 1966), linguists have sought to understand the plethora of factors underpinning and inciting sound change (Weinreich, Labov, and Herzog (1968). ${ }^{2}$

${ }^{1}$ This research has been funded by a collaborative grant from the Deutsche Forschungsgemeinschaft (BA 3080/3-1) and the Tübingen Universität Schwäbische Forschungsstipendium (TUSFS-2016-20).

${ }^{2}$ The authors would like to thank the following people for their review and feedback on earlier versions of this work: Peter Auer, Harald Baayen, Isabelle Buchstaller, Jenny Cheshire, Lauren Hall-Lew, Jonathan Harrington, Adrian Leemann, and Konstantin Sering. Any inaccuracies remaining are, of course, our own. 
Sociolinguistic explorations of small speech communities (e.g., Labov 1962; Wolfram and Schilling-Estes 1996) and psycholinguistic studies of large language corpora (e.g., Baayen 1996; Wieling et al. 2016) have become the norm in investigations of linguistic change. However, less research has been conducted by combining psycholinguistic analytical methods and sociolinguistic variationist approaches in examining small, ethnographically rich panel datasets. This chapter targets this deficit by analysing the intra- and extra-linguistic factors affecting an ongoing sound change in Swabian, an Alemannic dialect spoken in southwestern Germany, through the speech of 20 panel speakers recorded in two different communities, Stuttgart and Schwäbisch Gmünd, first in 1982 and again in 2017.

The target variable for the current investigation is the modern standard German diphthong [ai], which evolved from the merger of two different Middle High German (MHG) phonemes, /i:/ and /ei/ (Schwarz 2015:51,161) - a change that did not occur in the high German dialect of Swabian. The typical Swabian phonetic realisation of lemmata originating from the MHG phoneme /i:/ is [əi]; for example, the word Zeit (MHG /zi:t/) 'time' is pronounced [tsait] in standard German and [tsəit] in Swabian. The typical Swabian phonetic realisation of lemmata stemming from the MHG /ei/ is [oi]; for example, the word klein (MHG [klein]) 'small' is realised as [klain] in standard German and as [gloi] in Swabian. In contemporary Swabian, standard German [klain] also varies with a more centralised, vernacular realisation [gləi], which is the object of this study. The aim of this investigation is to explore the variation in lemmata stemming from these two MHG phonemes to determine whether the historical phonetic distinction is collapsing in modern Swabian, as has happened in modern standard German, such that [ai] and [əi] are becoming more similar to one another within the lifespan of one generation.

The /ai/ diphthong is an ideal variable for analysis in Swabian because: (1) it occurs with relatively high frequency in our corpus, (2) it is well-researched from a dialectology perspective, and, (3) it is a stereotypical and non-salient feature of the Swabian dialect (Russ 1990; Schwarz 2015). In analysing the /ai/ diphthongs based on the Sprachatlas des deutschen Reichs 'The Linguistic Atlas of Germany' (Wenker \& Wrede 1895) and the Südwestdeutscher Sprachatlas 'Linguistic Atlas of Southwest Germany' (Steger et al. 1989), Schwarz (2015:488) found statistically significant differences between lemmata based on their MHG origin. To our 
knowledge, no longitudinal sociolinguistic or psycholinguistic study has been conducted on the /ai/ diphthong in Swabian.

\section{RESEARCH BACKGROUND}

Starting with his seminal work in the 1960s, Labov introduced Sir Charles Lyell's (1833) UNIFORMITARIAN PRINCIPLE into sociolinguistics, claiming that "the forces operating to produce linguistic change today are the same kind and order of magnitude as those which operated in the past" (Labov 1972:275). According to this "apparent-time" approach, individuals, post-adolescence, do not substantially change their speech patterns throughout their lifespan (Labov 1994). However, this premise has proven to be problematic in many situations (e.g., Rickford and Price 2013; Sankoff and Wagner 2006). Do all individuals change in the same ways, at the same rates, and at the same points across their lifespan? And, do the grammars of individuals change along with the grammars of the communities of which they are a part?

Sociolinguistic studies have repeatedly found that both internal linguistic and external social factors influence the nature and direction of language change (Labov 1994; Labov 2001). Confounding these environmental influences are lexical frequency effects, a linguistic force that has received little attention in sociolinguistic variationist research, even less in longitudinal panel studies, and none to our knowledge in Swabian. Indeed, there is considerable controversy regarding the nature and impact of lexical frequency on linguistic processes and sound change. Bybee (2002) claims that frequently used words or phrases undergo 'special reduction', yielding differing results based on lexical word class and showing that synchronic change occurs first in more frequently used words and then progresses to the less frequent ones (Bybee 2017:273-275). Aylett and Turk (2006) further suggest that highfrequency words are usually found in contexts in which they are more predictable and therefore provide less information than low-frequency words, which, as a consequence, makes them more likely candidates for reduction. Other research has shown that once a sound change is in progress, it spreads faster through low-frequency words due to analogical processes, hence it is the high-frequency words that show more resilience to change (Hay et al. 2015). Tomaschek et al. (2018) maintain that since high-frequency words "get more practice," they are produced with better proficiency and hence are more resistant to change. Better proficiency, therefore, 
reduces variability, which is generally accepted to be a precursor to sound change (Weinreich et al. 1968). Based on a listener-oriented exemplar model, Todd, Pierrehumbert, and Hay (2019) propose that frequency effects interact with the discriminability of the phone. Their research shows that, when a sound change increases the similarity to other phones, then change occurs in high-frequency words first; conversely, when a sound change reduces the similarity to other phones, change occurs first in low-frequency words.

\section{OBJective AND HyPOTHESES}

The objective of the current study is to explore to what extent the two MHG phonemes, /i:/ and /ei/, are undergoing change in Swabian within the lifespan of the individual speaker, explicitly losing their historical phonetic contrast and merging or becoming more similar to each other. Investigating the loss of phonetic contrast across the lifespan of individual speakers allows us to explore evidence for the principle that speakers can and do change their grammars post-adolescence, and that such structural changes are not restricted to generational change (Sankoff \& Wagner 2006; Buchstaller 2015)

Given that the two MHG diphthongs have merged in standard German and considering the effects of dialect levelling occurring across Germany (Auer 2011; Schwarz 2019), we expect to see a greater loss of phonetic contrast in the later recordings from our panel speakers than in the earlier ones, indicating that speakers do change their grammars across their lifespan (HYPOTHESIS 1). In addition, given that metropolitan areas are more likely to promote innovations than smaller communities (Trudgill 1986; Nerbonne \& Heeringa 2007), we expect to observe a greater loss of phonetic contrast for speakers who live in the large urban centre of Stuttgart rather than in the mid-sized, semi-rural town of Schwäbisch Gmünd (HYPOTHESIS 2). Based on studies of dialect identity, local orientation, and interlocutor accommodation (Auer \& Hinskens 2005; Dodsworth 2017), we expect to find a greater loss of phonetic distinction between these diphthongs with speakers who have a low orientation toward Swabian (HYPOTHESIS 3).

In light of the prior studies on the /ai/ diphthong (Labov 1962; Schwarz 2015), we expect to observe the effects of the phonetic environment on diphthong production and change. Given that consonant voicing has been observed to have strong effects on the acoustic characteristics of vowels (Kluender et al. 1988) affecting its perceptual characteristics (Denes 1955), we focus 
primarily on voicing in this study and expect to find a greater loss of contrast in environments with following voiceless consonants as opposed to voiced ones (HYPOTHESIS 4). Finally, given the contradictory effects reported in the literature on word frequency and sound change (Hay et al. 2015; Wedel et al. 2013; Bybee 2002; Bybee 2017), we investigate whether the loss of phonetic contrast is stronger in words of high or of low frequency. As the current study focuses on a sound change that increases the similarity between two phones (Todd et al. 2019), we expect to find a greater loss of distinction in high-frequency words (HYPOTHESIS 5). In sum, in looking at the interaction effects across all of these different factors, we postulate that we will see a greater loss of phonetic contrast in later recordings (2017), in an urban setting (Stuttgart), in speakers with low orientation, in following voiceless environments, and with higher frequency words.

\section{Data and Methodology}

We first describe the data and the methodology employed in our investigation, providing a description of the corpus, the dependent and independent variables, and the statistical models used to analyse the data.

\section{PANel CoRpus}

Twenty native speakers of Swabian were recorded in the communities of Stuttgart and Schwäbisch Gmünd in 1982 and again in 2017. Stuttgart is a big urban metropolis with close to 630,000 inhabitants, and Schwäbisch Gmünd is a typical mid-sized, semi-rural German town of around 60,000 inhabitants. The comparison of these two localities thus provides the opportunity to investigate sound change from both an urban and a semi-rural perspective. The data were collected following a Labovian-style, semi-structured sociolinguistic interview (Labov 1984) covering topics about the speakers' childhood, hobbies, friends and family, knowledge of Swabian customs and icons, and participation in local cultural activities. Interviews were conducted in speakers' home, typically over coffee and cake, with the goal of creating a casual interview situation. Interviewers in 1982 and 2017 were matched for social characteristics (e.g., age, gender, education) to create an interview situation as similar as possible for the two recording periods. 


\section{Speakers}

The speakers comprise three women and four men from Stuttgart and six women and seven men from Schwäbisch Gmünd. The majority are of similar socioeconomic status (middle class) and in the same age group (18-25 years old in 1982 and 53-60 years old in 2017). Four speakers were in their early 50's in 1982 and hence in their late 80's in 2017. In 1982, the 20 interviews comprised 17.9 hours (1075 minutes), 18,430 words (tokens), and 3,158 types (unique words). In 2017, the 20 transcripts total 24.2 hours (1451 minutes), 21,553 tokens, and 3,877 types. The number of tokens per speaker or word was not capped; hence, the dataset is not balanced for phonological context or word type.

\section{Transcriptions}

Transcriptions were completed in ELAN (Wittenburg et al. 2006) by native German speakers, students at the University of Tübingen, and extracted into PRAAT 4.0 (Boersma \& Weenink 2015), with signals digitised at a sampling rate of $4.4 \mathrm{kHz}$ and a low pass filter at 2.2 kHz. The audio files were aligned with the orthographic transcription using the HiddenMarkov-Model based Forced Aligner (Rapp 1995), and the segment boundaries of each item of interest were manually corrected. Word types with [ai] at the onset were excluded, as onset positions in German are frequently articulated with creaky voice, an allophone of glottal stops rendering the extraction of vowel formants impossible (Pompino-Marschall \& Żygis 2010). Since the diphthong [əi] is not involved in the phonetic distinction between [ai] and [əi], these tokens were also excluded.

\section{Formant Frequencies}

The dataset was built in PRAAT by automatically extracting the first and second formants for the [ai] diphthongs every 2.5 milliseconds with the upper bound frequency set at $5500 \mathrm{~Hz}$ for the female speakers and $5000 \mathrm{~Hz}$ for the male speakers. Given the size of the dataset, no manual correction was applied. To reduce the effect of formant differences resulting from the physiological differences between speakers, we z-scaled the first and second formant for each speaker (Lobanov 1971). Tokens with F1 larger than $1500 \mathrm{~Hz}$ and F2 larger than $3000 \mathrm{~Hz}$, and diphthongs longer than 400 milliseconds were excluded. Table 1 shows the resulting number of types (i.e., unique words), tokens (i.e., instances of a word type), and data points (i.e., 
frequency measurements) of the [ai] diphthong in the Swabian panel corpus for each diphthong and recording year.

\section{-------- INSERT TABLE 1 ABOUT HERE -------}

\section{SWABIAN ORIENTATION}

Swabian identity, i.e., speakers' affinity toward Swabia and the Swabian language, was assessed through a Swabian Orientation Index (SOI), developed based on speakers' answers to 16 questions in the interview covering four themes: (1) their allegiance to Swabia and selfidentification as being Swabian; (2) their knowledge of Swabian culture and icons; (3) their attitudes toward the Swabian dialect; and (4) and their self-reported usage of Swabian or standard German with family, friends, relatives, teachers, colleagues, and others. Each question was rated on a five-point scale (from 1 for the lowest to 5 for the highest orientation), and the results were averaged to arrive at an individual index for each speaker for each year (see Beaman 2018). ${ }^{3}$ Because SOI values were unequally distributed across the subsets and to reduce the complexity of the analysis, factorial predictors were created for the ranked SOI values, and high and low values were determined by a median split.

Assessing 'dialect identity' is not without its methodological challenges. Trudgill (1986, 2008) argues that, rather than identity, speakers choice of linguistic variants stems from contact with speakers of different varieties, and this contact results in processes of "quasi-automatic accommodation in face-to-face interaction" (Trudgill 2008:241). Yet, no single factor can account for the myriad of influences in the sociolinguistic situation (Nagy et al. 2013; HallLew \& Yaeger-Dror 2014). Notions of local identity (Labov 2001; Eckert 1989), interlocutor accommodation (Auer \& Hinskens 2005; Bell 1984; Trudgill 1986; Giles et al. 1991), social networks (Milroy 1987), and ethnic orientation (Hoffman \& Walker 2010; Sharma 2011), along with traditional social and demographic characteristics, interact in ways that allow speakers to convey varying social identities through language. The questions in the Swabian Orientation Index (SOI) were selected to represent the myriad cultural practices, loyalty, pride,

\footnotetext{
${ }^{3}$ Principal components analysis (PCA) was conducted on subscales of the Swabian Orientation Index (SOI) (Swabian allegiance, Swabian culture, Swabian language attitudes, and Swabian language usage), which showed all to be significant predictors of the variation between Swabian and standard German.
} 
discrimination, social interaction, and interlocutor accommodation that best reflect a speaker's dialect identity.

\section{StATISTICAL MODELLING}

To account for the non-linear spatio-temporal behaviour of formants, we used Generalized Additive Mixed Models (GAMMs) (package $m g c v$, Version 1.8-23) (Wood 2011) for R Project, Version 3.0.2 (R Core Team 2014). GAMMs model nonlinear functional relations between a response variable and one or more covariates by means of "smooths" on the basis of thin plate regression splines. Because of their multi-dimensional appearance, GAMMs provide an effective method for visualising complex relationships between covariates and response variables. ${ }^{4}$ Non-linear interactions between numeric variables are fitted by means of "tensor product smooths". 5

We used the following set of predictors to fit F1/F2 frequencies:

- recording year (1982 versus 2017);

- speech community (Stuttgart versus Schwäbisch Gmünd);

- word frequency (numeric), calculated from the Swabian corpus;

- diphthong origin (MHG/i:/ versus MHG /ei/), based on DWDS ${ }^{6}$

- Swabian Orientation Index (SOI) (as defined above);

- articulatory environment, i.e., voicing of the following consonant (voiced, voiceless); since actual vowel duration varies considerably between instances, time in the diphthong was normalised between 0 and 1 to support GAMM modelling.

GAMMs provide two pieces of evidence to test a hypothesis. Statistical validity of an effect in a GAMM analysis is derived from (1) model comparisons between a more complex and a less complex model and (2) significant non-linear effects $(a=0.001)$, i.e., whether the $\mathrm{F} 1$ or $\mathrm{F} 2$ values show a curved behaviour across time in a given condition. Only when the

\footnotetext{
${ }^{4}$ For a detailed description of Generalized Additive Models and their application to non-linear data, see Tomaschek et al. (2018); in particular, see Wieling et al. (2016) who used GAMMs to investigate articulatory differences between Dutch dialects. For an introduction to spline smooths, see (Baayen et al. 2017).

${ }^{5}$ Time-dependent data usually results in autocorrelation (AR) of the residuals (i.e., the correlation between the residual at timepoint $\mathrm{T}$ and timepoint $\mathrm{T}+1)$. To account for this, we included an $\mathrm{AR}(1)$ parameter in each model. Due to lack of space, all model summaries, along with all analyses, can be inspected in the Supplementary Material, downloadable from (URL to be released upon publication).

${ }^{6}$ Etymological origins were dervied from DWDS - Digitales Wörterbuch der deutschen Sprache, Berlinbrandenburgische Akademie der Wissenschaften.
} 
addition of an effect significantly improves the model fit, and only when the effect is significantly non-linear, is it considered valid.

We fitted three different models in this study: (1) individual speaker differences between the two diphthongs across the lifespan, (2) effects of manner of articulation on the change in diphthong production across the years, and (3) group differences between the two diphthongs based on community, Swabian orientation, lexical frequency, and articulatory environment i.e., following voiced/voiceless consonant. To ensure homoscedasticity and the normal distribution of residuals, data points with residuals larger than 2.5 standard deviations from the mean were excluded, and each model was refit. We first review an example analysis to demonstrate how we developed the models to test our hypotheses. In the subsequent Analysis and Results section, we report on the specifics of each model and discuss our findings.

\section{EXAMPLE ANALYSIS}

Using Stuttgart 1982 by way of example, Figure 1 demonstrates how we used GAMMs to analyse the F1 and F2 formant trajectories in determining the difference between the MHG /i:/ and MHG /ei/ diphthongs. This approach was followed for all subsequent models.

\section{Formant Trajectories}

The top panel of Figure 1 shows the predicted trajectories for both years and both diphthongs in each community (plotted with data obtained from the get_predictions() function from the itsadug package, Version 2.3, van Rij et al. 2017). The predicted trajectories were obtained from two models, each fitting F1/F2 values with a smooth for time interacting with a multi-level predictor for community by year by diphthong. Inverted F1 values are plotted on the $\mathrm{y}$-axis indicating vowel height, and inverted F2 values are plotted on the $\mathrm{x}$-axis representing fronting or backing (the left of the figure denotes the front of the mouth). The black dot indicates the onset of the diphthong, and curly brackets show the anchor vowels, $\{i\}$ and $\{$ a $\}$. Solid lines designate diphthongs stemming from MHG/i:/ origin and dashed lines those with MHG /ei/ origin. Grey lines represent speakers in 1982 and black lines speakers in 2017.

INSERT FIGURE 1 ABOUT HERE ----- 
The middle and bottom panels of Figure 1 provide an example to illustrate how we calculated the difference between the two diphthongs. The middle panels show the smooth of $\mathrm{F} 1$ and F2 across time for the two diphthongs. Lemmata originating from the MHG /i:/ phoneme (solid line) show a larger excursion than those stemming from MHG /ei/ (dashed line). The bottom panels depict the estimated difference between the F1/F2 trajectories for the two diphthongs across time on the y-axis (calculated with the plot_diff() function from the itsadug package). Using a confidence interval of two standard deviations $(\alpha<0.05)$, the two trajectories for F1 are significantly different between the time intervals 0.2 and 0.7 and the time intervals 0.9 and 1.0, as highlighted by the dark line on the x-axis. For F2, MHG /ei/ has significantly higher values than MHG /i:/ across the entire time interval.

\section{Total Euclidean Distance Squared}

To determine to what extent the two diphthongs have become more or less similar in 2017 compared with 1982, we developed the measure "Total Euclidean Distance Squared" (TEDS) to operationalise how sharply the two trajectories differ. As opposed to other methods that use simple Euclidean distance or Pillai scores to calculate differences on the basis of means (Nycz \& Hall-Lew 2014), TEDS allows us to measure the distance between the two diphthongs across time in spite of their non-linear behaviour. TEDS is defined by the following formula:

$$
T E D S=\sum_{i=1}^{n}\left(\sqrt{\Delta_{F 1}^{2}+\Delta_{F 2}^{2}}\right)^{2}
$$

where $\Delta_{\mathrm{F} 1}$ and $\Delta_{\mathrm{F} 2}$ denote the vectors of the point-wise differences between the F1/F2 trajectories of the two diphthongs (as illustrated in the bottom panels of Figure 1) and $n$ denotes the length of the vectors (i.e., number of data points) in the F1/F2 trajectory. Note that the square root term defines the Euclidean distance for each predicted data point, which more strongly penalises large distances between the trajectories than small ones. By definition, any TEDS greater than zero represents a significant difference between the F1/F2 trajectories of the two diphthongs. ${ }^{7}$

\footnotetext{
${ }^{7}$ TEDS was calculated in the Lobanov-normalized vowel space to serve as a heuristic: zero represents complete identity between the two trajectories, whereas increasing values represent increasing differences.
} 
In our example model, the TEDS for the Stuttgart speakers in 1982 was 9.6; by 2017, it has shrunk to 4.1, signalling that the two diphthongs have indeed become more similar over the 35-year time-span. In comparison, the TEDS for the Schwäbisch Gmünd speakers in 1982 was 23.1, shrinking to 15.0 in 2017 , also showing a loss of phonetic contrast. The overall smaller TEDS in Stuttgart suggests that this sound change is further advanced in Stuttgart than in Schwäbisch Gmünd. Following this methodological framework, we now turn to a full analysis of the change in the Swabian [ai] diphthongs over the 35 years.

\section{Analysis and Results}

Our analysis of the change in the realisation of the [ai] diphthong comprises two aspects: individual change across speakers' lifespans and group change based on community, Swabian orientation, lexical frequency, and following phonetic environment, i.e., voicing.

\section{LIFESPAN CHANGE}

There is ample research that shows individuals, for a variety of reasons, do not always follow community trends. Sankoff (2018) points out that people have options: "some people ... maintain early-acquired patterns, others participate in the change, and still others reject it in favor of the conservative norms of previous generations." In panel literature, these three scenarios have become known, respectively, as LIFESPAN CHANGE, speakers moving in the direction of the overall community change, SPEAKER STABILITY, speakers resisting the community change, and, RETROGRADE CHANGE, speakers moving in the opposite direction of the community change (Sankoff 2019).

\section{Modelling}

To investigate individual speaker change across the lifespan, we separated the data by community (Schwäbisch Gmünd, Stuttgart) and fit the F1 and F2 formant values with a smooth for time in each subset, interacting with speaker and diphthong. ${ }^{8}$

\section{----- INSERT FIGURE 2 ABOUT HERE -----}

\footnotetext{
${ }^{8}$ All models contain random intercepts for word and speaker gender. Unless otherwise mentioned, all model terms were significantly non-linear (alpha $=0.0001)$.
} 
Results

Figure 2 plots the TEDS for each speaker: 1982 values are shown on the $\mathrm{x}$-axis and 2017 values on the y-axis. Solid squares represent speakers from Schwäbisch Gmünd, and open circles mark speakers from Stuttgart. Recall that all distances larger than zero are significant. The dashed diagonal line represents equal TEDSs in 1982 and 2017, and the solid grey diagonals delineate TEDSs greater than 10 and less than $-10 .{ }^{9}$ The lower or higher a speaker is in relation to the diagonal, the lessor or greater the degree of change in their diphthongs across the years. Markus, Rupert and Ema show the greatest TEDS change, and Pepin, Herbert, and Anneliese the least. Most speakers fall either on or below the dotted diagonal, indicating a smaller distance between the two diphthongs in 2017 than in 1982 and providing support for our first hypothesis that the two diphthongs are collapsing and losing their phonetic contrast across the lifespans' of these individuals.

\section{----- INSERT TABLE 2 ABOUT HERE -----}

Table 2 shows the summary values for each speaker, sorted by TEDS, quantitatively demonstrating the sound change continuum. For explanatory purposes, we have parsed the speakers into Sankoff's three lifespan trajectory types: CHANGE, STABILITY, RETROGRADE. The five speakers at the top of the table exhibit the most extreme change between 1982 and 2017 (i.e., TEDS less than -10). These speakers are losing the phonetic contrast between the two diphthongs, moving in the direction of the community trend and levelling with the standard language (LIFESPAN CHANGE). Markus and Rupert from Schwäbisch Gmünd show an almost complete collapse of the two diphthongs. Both travel and work extensively outside of their home town, Markus as a high-tech marketing executive based in Munich, and Rupert as a lecturing and consulting sociologist based in Tübingen. Their careers have broadened their social networks and dialect identities outside of their homeland, bringing them into more frequent contact with standard German speakers and constraining their Swabian identity. Rupert feels that speaking Swabian is a sign of lack of education, and Markus wants his children to learn standard German so they will have improved opportunities on the job market.

\footnotetext{
${ }^{9} \mathrm{We}$ chose 10 as a cutoff as a means to differentiate the speakers who show the greatest distances.
} 
The speakers in the middle of Table 2 are those for whom the distinction between the two diphthongs has changed minimally or not at all (SPEAKER STABILITY) (i.e., TEDS between -10 and 10). Five are from Schwäbisch Gmünd, mother and daughter, Louise and Elke, and cousins, Berdine, Jurgen, and Alf. The stable group also includes two siblings from Stuttgart, Ricarda and Egbert, and Egbert's best friend, Manni. Except for Berdine, all speakers have lived and worked their entire lives in their Swabian communities. All have remained stable in their careers, seven of the twelve are elementary or middle school teachers. As a result, these speakers have experienced few dialect influences beyond Swabia that would stimulate change.

Finally, there are three speakers (at the bottom of Table 2 and above the upper solid grey diagonal in Figure 2) who are moving against the community trend and retaining the phonetic contrast between the two diphthongs, RETROGRADE CHANGE. Based on our ethnographic investigations of the speakers within their communities, we know that these speakers have lived and worked in Swabia (or southern Germany/Switzerland in the case of Anneliese) for their entire lives. Herbert and Pepin are both retired. Sociolinguistic theory hypothesises that speakers revert to more conservative dialect features later in life once they have retired and moved out of the linguistic market (Sankoff \& Wagner 2006; Chambers 1997; Buchstaller et al. 2017). Our speaker's attitudes in later life support this interpretation. Anneliese remarks, ich bin eigentlich gern eine Schwäbin. 'I like being Swabian.' mir gefällt der Dialekt. 'I like the dialect.' mir gefällt die Landschaft. 'I like the countryside.' mir gefällt es im Schwabenländle. 'I like it in little Swabia. ${ }^{10}$

\section{----- INSERT FIGURE 3 ABOUT HERE -----}

Figure 3 depicts the individual diphthong trajectories for each speaker for the two diphthongs in both years, sorted from the smallest TEDS to the largest. The solid lines represent diphthongs with MHG /i:/ origin and dashed lines those with MHG /ei/ origin; grey lines represent speakers in 1982 and black lines speakers in 2017. The individual trajectories clearly illustrate the substantial distinction between the diphthongs for those at the top of the

\footnotetext{
${ }^{10}$ Schwabenländle 'little Swabia', with the use of the Swabian diminutive affix, is a term of endearment.
} 
figure and the almost complete overlap between the diphthongs for those at the bottom of the figure.

\section{PhONetic ChANGE}

We next look at the differences between the MHG /i:/ and /ei/ diphthong production depending on the manner and type of articulation. Given the robust effects of anticipatory coarticulation in the preceding environment, we elected to consider only the following environment in our analysis (Tomaschek et al. 2018; Hoole et al. 1993; Sziga 1992).

\section{Modelling}

We separated the data by community and fit the F1/F2 formant values with a smooth including a Time * Manner * Voicing * Year * MHG origin interaction.

\section{Results}

Figure 4 shows the TEDS for each community depending on the manner of articulation for the following consonant. Solid circles represent voiced consonants and open circles voiceless consonants. 1982 is shown on the $\mathrm{x}$-axis and 2017 on the y-axis. The diagonal dashed line represents equal TEDS values in 1982 and 2017. The data reveal that speakers in Schwäbisch Gmünd (left panel) exhibit larger TEDSs in both years for diphthongs followed by plosives (both voiced and voiceless) than by other manners of articulation. The smallest TEDS is present in 2017 when the diphthong is articulated in an open syllable (TEDS $=22$ ) followed by voiced sonorants (TEDS $=30$ ), which may be attributed to the co-articulatory aspects of the sonorant's vowel-like quality (Hickey 2004:12). We see a similar pattern in Stuttgart (right panel) with open syllables (TEDS $=40)$ and voiced sonorants (TEDS $=39$ ) showing smaller TEDSs in 2017 than in 1982. However, in contrast to Schwäbisch Gmünd, Stuttgart speakers appear to have become more sensitive to plosives in 2017: while they show significantly smaller TEDSs in 2017 in all environments, this effect is strongest for plosives (showing TEDSs from 50 (voiceless) an 85 (voiced) to 15 and 20, respectively).

\section{----- INSERT FIGURE 4 ABOUT HERE -----}


The TEDS reductions we see in 2017 suggest that our panel data captures a potential merger in progress by revealing a loss of phonetic contrast between the two MHG diphthongs across the two recording years (HYPOTHESIS 1), favoured by following plosives, then voiceless sonorants and fricatives. While the constraints for the two communities are essentially the same, the sound change appears to have progressed further for speakers in Stuttgart than for those in Schwäbisch Gmünd, supporting our hypothesis that the urban centre of Stuttgart is leading this change in progress (HYPOTHESIS 2).

\section{INTERACTIONAL ANALYSIS OF CHANGE IN PROGRESS}

We now evaluate the interactional effects influencing change in the realisation of the MHG /i:/ and /ei/ diphthongs based on community, Swabian orientation, lexical frequency, and voicing of the following consonant. Due to limitations with the size of our database, we decided to move forward with a binary voiced/voiceless distinction as most representative of the phonetic environment.

\section{Modelling}

For this model, we split the data by community and then fitted the F1/F2 formant values with a tensor containing a six-way interaction: Time * Frequency * Swabian Orientation* MHG origin * Year * Voicing. Model comparison using a $\chi 2$-test indicated that the inclusion of Voicing in the interaction provided a better model fit for F1 values but not for F2. Hence, F2 was fitted with a five-way interaction: Time * Frequency $*$ Swabian Orientation * MHG origin * Year. All models contained random intercepts for speaker and word. ${ }^{11}$ We calculated TEDS based on these models for each combination of factors: Community, Year, Swabian Orientation, Frequency, and Voicing. For Voicing, we predicted the trajectories for the $25^{\text {th }}$ and $75^{\text {th }}$ percentile of the frequency distribution. In total, we obtained 32 TEDS values ( 2 diphthongs $* 2$ SOI levels $* 2$ frequencies $* 2$ voicing/voiceless $* 2$ communities).

\section{----- INSERT FIGURE 5 ABOUT HERE -----}

\footnotetext{
${ }^{11}$ Model comparisons and model summaries can be found in the Supplementary Materials, which can be downloaded from https://osf.io/nfqt3/.
} 


\section{Results}

Figure 5 illustrates the best-fit results from the modelling effort: TEDS is shown on the yaxis and frequency and voicing on the x-axis. Overall, the TEDS values were smaller in 2017 (solid circles and triangles) than in 1982 (open circles and triangles), confirming our first hypothesis regarding the loss of contrast between these diphthongs over the years. Speakers from Schwäbisch Gmünd (left panel) show larger TEDS than speakers from Stuttgart (right panel), confirming our second hypothesis that we would find a greater loss of contrast in an urban environment rather than in a mid-sized, semi-rural setting. As we expected, low SOI speakers (circles) produce smaller TEDS, exhibiting a greater loss of contrast, than high SOI speakers (triangles), confirming our third hypothesis that high orientation to Swabian would restrict innovation and promote retention of conservative dialect forms. The details of the change, however, depend heavily on the interaction between predictors.

First, we consider the effects of frequency and voicing. In Schwäbisch Gmünd, independent of year, SOI, and frequency, voiceless consonants show the lowest TEDS, hence the smallest distinction between the diphthongs. With high-frequency words, the TEDS are starkly reduced for all factors in voiceless environments, yet with low-frequency words, the voicing distinction is not as paramount, except with high SOI speakers in 2017 who show a considerable TEDS peak (discussed further below). These results confirm our fourth hypothesis that the acoustic characteristics of vowel production would be sensitive to voicing, and implicates voicing as the main predictor impelling the loss of phonetic contrast between these diphthongs, at least for these 20 speakers in the community of Schwäbisch Gmünd.

Because this sound change increases the similarity between the two phones, our fifth hypothesis predicted a greater loss of phonetic contrast in high-frequency over low-frequency words. While this holds for high-frequency words in voiceless environments, for lowfrequency words, there is no difference between the predictors. However, this effect interacts with SOI, which shows lower TEDS and a greater loss of phonetic contrast for low SOI speakers. In high-frequency words, low SOI speakers show the smallest TEDS, while high SOI speakers show only minor TEDS reduction over the years. In contrast, with low-frequency words, both high and low SOI speakers increased their TEDS over the years, with high SOI speakers showing a spike from 1982 to 2017, signifying the potential effect of "hypercorrection" at play (explored further in the Discussion section). This interaction between 
frequency and SOI potentially contradicts our frequency-based prediction, unless the effects of SOI are taken into consideration. These findings bring to light the powerful interactive effect that socio-cognitive factors such as Swabian orientation, in combination with linguistic constraints such as frequency and voicing, have on sound change.

Turning to Stuttgart, the effects on the loss of contrast between the diphthongs are less pronounced. The TEDS have declined from 1982 to 2017 but only with high SOI speakers using high-frequency words in voiced environments. For the other environments, the effects are much smaller, which we surmise is because this sound change is currently in progress and may even be nearing completion in Stuttgart. Supporting this position, we see that high SOI speakers in 2017 produce TEDS similar to low SOI speakers in 1982. In all other predictor combinations, there is no major change in Stuttgart. We surmise that, apart from the highfrequency words followed by voiced consonants uttered by high SOI speakers, the Stuttgart community had already begun to lose the diphthong contrast in 1982 . Hence, we can conjecture that this change will continue its trajectory and progress to high-frequency words in voiced environments to complete the change.

\section{Discussion}

Our analysis of 20 panel speakers unveils an intricate set of interacting factors affecting the loss of phonetic contrast between the two diphthongs of MHG origin in modern Swabian. Our findings indicate that "speakers' internal grammars are more labile than we would expect" (Buchstaller et al. 2017:26) and that the loss of phonetic contrast between the traditional Swabian diphthongs is well underway across the lifespan of our panel speakers. Given that the two diphthongs were less differentiated in Stuttgart than in Schwäbisch Gmünd, our findings support the Gravity (Trudgill 1986) and Cascade (Labov 2003) models which claim that change begins in big urban centres and spreads to smaller communities. Most revealing in our findings is how the community of Schwäbisch Gmünd in 2017 mirrors the community of Stuttgart in 1982, conceivably marking the origin and trajectory of the change. It appears that this change was already in progress in Stuttgart in 1982 and has begun to emerge in Schwäbisch Gmünd in 2017 with low SOI speakers. However, high SOI speakers in Schwäbisch Gmünd are resisting the change and continuing to maintain a resilient distinction between the two diphthongs. 
So what has prompted low SOI speakers to start adopting this innovation and why are high SOI speakers resisting it? We contend that this change is a reflection of the immense societal transformation that has occurred in Germany (indeed across western Europe) over the last 30 years. Rising levels of education (e.g., Ammon 2001; Schwarz 2019), ever-increasing mobility (e.g., Auer 2007; Britain 2013, 2016), pervasive dialect contact and levelling (e.g., Auer 2011; Buchstaller et al. 2017), and ubiquitous peer-pressure (e.g., Conrad 2017) are restricting the role of Swabian in daily life. Hence it is not surprising that this change is further advanced with speakers who have lost (or are losing) their Swabian identity. Much research has shown (e.g., Labov 1962; Wolfram \& Schilling-Estes 1996) that diphthong trajectories project notions of local identity (e.g., locals who feel their traditional way of life is being threatened with the encroachment of modernisation). Wieling and his colleagues have supported these findings with data from the Netherlands and Italy, showing that larger, richer and younger communities move away from the dialect and toward the standard language (Wieling et al. 2011; Wieling et al. 2014). Conrad (2017) reports similar effects for the younger generation in Luxembourg. Our findings indicate that local orientation and dialect identity play a significant role in language change, inciting or retarding the adoption of innovations.

The rate of change between 1982 and 2017 is smaller in Stuttgart than in Schwäbisch Gmünd, yielding support to our argument that the change was already in progress in Stuttgart in 1982, which provided less room for change. Speakers in Stuttgart increased the distance between the two diphthongs in low-frequency words. One explanation for this apparent reversal might lie in the evolving status of the dialect vis-à-vis the standard language (Auer \& Spiekermann 2011; Preston \& Robinson 2005). Despite the external forces mentioned above, Swabian appears to be losing some of the stigma it had 30 years ago. Winfried Kretschmann, the governor of Baden-Württemberg, a proud proponent of Swabian, exclaims, ich spreche schwäbischer als früher, 'I speak more Swabian-like now than before' (Frankfurter Allgemeine Zeitung 2018). ${ }^{12}$

On the surface, our findings appear to contradict Todd et al.'s (2019) hypothesis regarding the effects of contrastive categories and word frequency, unless the impact of socio-cultural

\footnotetext{
${ }^{12}$ Kretschmann is 70 years, approaching retirement age, hence his return to his Swabian roots might be explained by the sociolinguistic principle that speakers revert to more conservative dialect features later in life.
} 
factors such as dialect identity are taken into account. ${ }^{13}$ Additionally, high SOI speakers may be resisting the innovation in high-frequency words due to Tomaschek et al.'s (2019) finding that high-frequency words are more resistant to change since they are more deeply entrenched in the lexicon. Finally, the interaction between SOI and frequency may be related to speaker saliency and accommodation: since they occur more often, high-frequency words are more salient, hence low SOI speakers desiring to sound more standard may be accommodating by reducing the diphthong contrast in word they use more often.

The interaction between dialect identity and language change, as operationalised by word frequency, cannot be discounted. The effects of lexical frequency in our study point to the powerful interaction between internal linguistic processes and external societal forces. Three findings from Schwäbisch Gmünd underscore this point. First, high SOI speakers are resisting the change and retaining a robust distinction between the diphthongs in high-frequency words. Second, both low and high SOI speakers in Schwäbisch Gmünd increased the contrast between the diphthongs from 1982 to 2017 in low-frequency words, resisting the innovation and retaining this solid marker of Swabian identity. Third, high Swabian oriented speakers in Schwäbisch Gmünd appear to be hypercorrecting in 2017 with low-frequency words, holding on to the conservative diphthong distinction. The effects of hypercorrection are well established in the hegemony of the standard language. As Trudgill (1992:78) notes, "it is clear that hypercorrection gives rise at the macro leve1 to large-scale linguistic change and results in interdialect forms becoming an integral part of a particular dialect."

In sum, Milroy (2003:163) maintains that "changing local ideologies shape trajectories of linguistic change" and shifting indexicalities help speakers preserve or unleash their linguistic identities in ways that reflect their individual lifespan trajectories and reflect what is important to them. In Swabia, the indexicalities and social meaning of the [ai] diphthong variants reflect these perspectives: speakers like Rupert and Markus index progress and success by adopting innovative, supralocal forms. Speakers such as Anneliese and Siegfried, on the other hand, impart the traditional values of "home and hearth" by conserving the historical diphthong distinction. The choice to speak Swabian or not is confirmed by prolific comments in the interviews. Pepin, with his low Swabian orientation, commented, von dem her war i mal

\footnotetext{
${ }^{13}$ One difference between the current study and Todd et al.'s which could be producing differing results is that they focused only on monosyllabic words, whereas we include longer, more distinctive words.
} 
typisch und zum Glück nimme so arg 'at that time [when I was a Schwab] I was typical and luckily not so much anymore', while Louise, with her high orientation to Swabia(n), exclaimed, $i$ bin e Schwââb und bleib ôiner 'I'm a Schwab and will stay one'.

\section{References}

Ammon, U., 2001. Dialect as an Educational and Social Challenge. Euskalkia eta hezkuntza. Mendebalde Euskal Kultur Elkartea, pp.201-225.

Auer, P., 2011. Dialect vs. standard: A typology of scenarios in Europe. In B. Kortmann \& J. van der Auwera, eds. The Languages and Linguistics of Europe: A Comprehensive Guide. Berlin: De Gruyter Mouton, pp. 485-500.

Auer, P., 2007. Mobility, contact and accommodation. In C. Llamas, L. Mullany, \& P. Stockwell, eds. The Routledge Companion to Sociolinguistics. London: Routledge, pp. 109-115.

Auer, P. \& Hinskens, F., 2005. The role of interpersonal accommodation in a theory of language change. In P. Auer, F. Hinskens, \& P. Kerswill, eds. Dialect Change: Convergence and Divergence in European Languages. Cambridge: Cambridge University Press, pp. 335-357.

Auer, P. \& Spiekermann, H., 2011. Demotisation of the standard variety or destandardisation? The changing status of German in late modernity (with special reference to southwestern Germany). In T. Kristiansen \& N. Coupland, eds. Standard Languages and Language Standards in a Changing Europe. Oslo: Novus Press.

Aylett, M. \& Turk, A., 2006. Language redundancy predicts syllabic duration and the spectral characteristics of vocalic syllable nuclei. Journal of Acoustic Society of America, 119(5), pp.30483058 .

Baayen, R.H. et al., 2017. The cave of shadows: Addressing the human factor with generalized additive mixed models. Journal of Memory and Language, 94, pp.206-234.

Baayen, R.H., 1996. The effects of lexical specialization on the growth curve of the vocabulary. Computational Linguistics, 22(4), pp.455-480. Available at: http://www.aclweb.org/anthology/J96-4001.pdf.

Beaman, K. V., 2018. Identity and place: The changing role of Swabian in modern Germany. In Conference on Language, Place and Periphery. University of Copenhagen. January 18-19, 2018.

Bell, A., 1984. Language style as audience design. Language in Society, 13(2), pp.145-204.

Boersma, P. \& Weenink, D., 2015. Praat: doing phonetics by computer (Version 5.1.13).

Britain, D., 2016. Sedentarism and nomadism in the sociolinguistics of dialect. In N. Coupland, ed. Sociolinguistics: Theoretical Debates. Cambridge: Cambridge University Press, pp. 217-241.

Britain, D., 2013. Space, diffusion and mobility. In J. K. Chambers \& N. Schilling, eds. The Handbook of Language Variation and Change. Wiley-Blackwell. 
Buchstaller, I., 2015. Exploring linguistic malleability across the life span: Age-specific patterns in quotative use. Language in Society, 44(4), pp.457-496.

Buchstaller, I. et al., 2017. Levelling across the life-span?: Tracing the FACE vowel in panel data from the North East of England. Journal of Sociolinguistics, 21(1), pp.3-33.

Bybee, J.L., 2007. Frequency of use and the organization of language, Oxford: Oxford University Press.

Bybee, J.L., 2017. Grammatical and lexical factors in sound change: A usage-based approach. Language Variation and Change, 29, pp.273-300.

Bybee, J.L., 2002. Word frequency and context of use in the lexical diffusion of phonetically conditioned sound change. Language Variation and Change, 14(3), pp.261-290.

Chambers, J.K., 1997. Sociolinguistic coherence of changes in a standard dialect. University of Pennsylvania Working Papers in Linguistics, 4(1), pp.171-184.

Conrad, F., 2017. Variation durch Sprachkontakt: Lautliche Dubletten im Luxemburgischen, Peter Lang Gmbh.

Denes, P., 1955. Effect of Duration on the Perception of Voicing. The Journal of the Acoustical Society of America, 27(4), pp.761-764.

Dodsworth, R., 2017. Migration and Dialect Contact. Annual Review of Linguistics, 3, pp.331-346.

Eckert, P., 1989. Jocks and Burnouts: Social Categories and Identity in the High School, New York: Teachers College Press.

Frankfurter Allgemeine Zeitung, 2018. “Ich spreche schwäbischer als früher”. An Interview with Winfried Kretschmann. Monatlicher Magazin, (April), pp.60-61.

Giles, H., Coupland, N. \& Coupland, J., 1991. Accommodation theory: Communication, context, and consequence. In H. Giles, N. Coupland, \& J. Coupland, eds. Contexts of Accommodation:

Developments in Applied Sociolinguistics. Studies in Emotion and Social Interaction. Cambridge: Cambridge University Press.

Hall-Lew, L. \& Yaeger-Dror, M., 2014. New perspectives on linguistic variation and ethnic identity in North America. In L. Hall-Lew \& M. Yaeger-Dror, eds. Language and Communication. Edinburgh Research Explorer, pp. 1-8.

Hay, J. et al., 2015. Tracking word frequency effects through 130 years of sound change. Cognition, 139, pp.83-91.

Hickey, R., 2004. Mergers, near-mergers and phonological interpretation. In C. J. Kay, C. Hough, \& I. Wotherspoon, eds. New Perspectives on English Historical Linguistics. Amsterdam: John Benjamins, pp. 125-137.

Hoffman, M.F. \& Walker, J.A., 2010. Ethnolects and the city: Ethnic orientation and linguistic variation in Toronto English. Language Variation and Change, 22, pp.37-67.

Hoole, P., Nguyen-Trong, N. \& Hardcastle, W., 1993. A Comparative Investigation of Coarticulation in 
Fricatives: Electropalatographic, Electromagnetic, and Acoustic Data. Language and Speech, $36(2,3)$, pp.235-260.

Kluender, K.R., Diehl, R.L. \& Wright, B.A., 1988. Vowel-length differences before voiced and voiceless consonants: An auditory explanation. Journal of Phonetics, 16(April), pp.153-169.

Labov, W., 1984. Field methods of the project Linguistic Change and Variation. In J. Baugh \& J. Scherzer, eds. Language in Use: Readings in Sociolinguistics. Englewood Cliffs NJ: Prentice Hall, pp. 28-53.

Labov, W., 1994. Principles of Linguistic Change, Volume I, Internal Factors (Language in Society), Oxford: Blackwell Publishing.

Labov, W., 2001. Principles of Linguistic Change, Volume II, Social Factors, Malden: Blackwell Publishing.

Labov, W., 2003. Pursuing the cascade model. In D. Britain \& J. Cheshire, eds. Social Dialectology: In Honour of Peter Trudgill. Amsterdam: John Benjamins Publishing Company, pp. 9-22.

Labov, W., 1972. Sociolinguistic Patterns, Philadelphia: University of Pennsylvania.

Labov, W., 1962. The social history of a sound change on the island of Martha's Vineyard. Master's Thesis. Columbia University.

Labov, W., 1966. The Social Stratification of English in New York City 2nd ed., Cambridge: Cambridge University Press.

Lobanov, B.M., 1971. Classification of Russian vowels spoken by different speakers. Journal of Acoustic Society of America, 49, pp.606-608.

Lyell, C., 1833. Principles of Geology, Being an Attempt to Explain the Former Changes of the Earth's Surface, by Reference to Causes Now in Operation. In Three Volumes, London: John Murray, Albemarle-Street.

Milroy, L., 1987. Language and Social Networks, Second Edition (first published in 1980). Oxford: Basil-Blackwell.

Milroy, L., 2003. Social and linguistic dimensions of phonological change: Fitting the pieces of the puzzle together. In D. Britain \& J. Cheshire, eds. Social Dialectology: In Honour of Peter Trudgill. Amsterdam: John Benjamins Publishing Company, pp. 155-171.

Nagy, N., Chociej, J. \& Hoffman, M.F., 2013. Analyzing Ethnic Orientation in the Quantitative Sociolinguistic Paradigm. Language and Communication, 35(1), pp.9-26.

Nerbonne, J. \& Heeringa, W., 2007. Geographic distributions of linguistic variation reflect dynamics of differentiation. In W. Sternefeld \& S. Featherston, eds. Roots: linguistics in search of its evidential base. Walter de Gruyter GmbH, pp. 267-298.

Nycz, J. \& Hall-Lew, L., 2014. Best practices in measuring vowel merger. Proceeding of Meetings on Acoustics, 20(60008), pp.1-19.

Pompino-Marschall, B. \& Żygis, M., 2010. Glottal marking of vowel-initial words in German. ZAS 
Papers in Linguistics, 52, pp.1-17.

Preston, D.R. \& Robinson, G.C., 2005. Dialect Perception and Attitudes to Variation. In Clinical Sociolinguistics. Malden MA: Blackwell Publishing, pp. 133-150.

R Core Team, 2014. R: A Language and Environment for Statistical Computing, Vienna, Austria: R Foundation for Statistical Computing. Available at: http://www.r-project.org.

Rapp, S., 1995. Automatic phonemic transcription and linguistic annotation from known text with hidden Markov models: An aligner for German. Proceedings of ELSNET Goes East and IMACS Workshop, (February).

Rickford, J.R. \& Price, M., 2013. Girlz II women: Age-grading, language change and stylistic variation. Journal of Sociolinguistics, 17(2), pp.143-179.

van Rij, J. et al., 2017. R Package “itsadug” (Version 2.3).

Russ, C.V.J., 1990. The Dialects of Modern German: A Linguistic Survey, Oxford: Routledge.

Sankoff, G., 2019. Language Change Across the Lifespan: Three Trajectory Types. Language, 95(2), pp.1-36.

Sankoff, G. \& Wagner, S.E., 2006. Age grading in retrograde movement: The inflected future in Montreal French. Penn Working Papers in Linguistics, 12.2 Selec(2), pp.203-216.

Schwarz, C., 2015. Phonologischer Dialektwandel in den alemannischen Basisdialekten Südwestdeutschlands im 20. Jahrhundert: Eine empirische Untersuchung zum Vokalismus, Stuttgart: Franz Steiner Verlag.

Schwarz, C., 2019. Reduction and persistence of phonological dialect features in German. In M. Cerruti \& S. Tsiplakou, eds. Koines and regional standard varieties: Structural and sociolinguistic aspects of language shift. Studies in Language Variation. Amsterdam/Philadelphia: John Benjamins.

Sharma, D., 2011. Style Repertoire and Social Change in British Asian English. Journal of Sociolinguistics, 15(4), pp.464-492.

Steger, H., Gabriel, E. \& Schupp, V., 1989. Südwestdeutscher Sprachatlas “Linguistic Atlas of Southwest Germany, " Marburg: Elwert.

Sziga, E.C., 1992. Acoustic evidence for gestural overlap in consonant sequences. Haskins Laboratories Status Report on Speech Research, SR-111/112, pp.43-62.

Todd, S., Pierrehumbert, J.B. \& Hay, J., 2019. Word frequency effects in sound change as a consequence of perceptual asymmetries: An exemplar-based model. Cognition, 185, pp.1-20.

Tomaschek, F. et al., 2018. Practice makes perfect: The consequences of lexical proficiency for articulation. Linguistic Vanguard, 4(s2), pp.1-13.

Trudgill, P., 2008. Colonial dialect contact in the history of European languages: On the irrelevance of identity to new-dialect formation. Language in Society, 37(2), pp.241-254. 
Trudgill, P., 1992. Dialect contact, dialectology and sociolinguistics. In K. Bolton \& H. Kwok, eds. Sociolirrgiristics Today: International Perspectrves. London: Routledge, pp. 71-79.

Trudgill, P., 1986. Dialects in Contact, Oxford: Blackwell Publishing.

Wedel, A., Kaplan, A. \& Jackson, S., 2013. High functional load inhibits phonological contrast loss: A corpus study. Cognition, 128(2), pp.179-186.

Weinreich, U., Labov, W. \& Herzog, M.I., 1968. Empirical foundations for a theory of language change. In W. Lehmann \& Y. Malkiel, eds. Directions for Historical Linguistics. Austin: University of Texas., pp. 95-188.

Wenker, G. \& Wrede, F., 1895. Der Sprachatlas des deutschen Reichs "The Linguistic Atlas of Germany," Elwert.

Wieling, M. et al., 2016. Investigating dialectal differences using articulography. Journal of Phonetics.

Wieling, M. et al., 2014. Lexical differences between Tuscan dialects and standard Italian: Accounting for geographic and socio-demographic variation using generalized additive mixed modeling. Language, 90(3), pp.669-692.

Wieling, M., Nerbonne, J. \& Baayen, R.H., 2011. Quantitative social dialectology: Explaining linguistic variation geographically and socially. PLoS ONE, 6(9), pp.1-14.

Wittenburg, P. et al., 2006. ELAN: A professional framework for multimodality research. Proceedings of the Fifth International Conference on Language Resources and Evaluation (LREC), pp.15561559.

Wolfram, W. \& Schilling-Estes, N., 1996. On the social basis of phonetic resistance: The shifting status of Outer Banks /ay/. In J. Arnold et al., eds. Sociolinguistic variation: Data, theory and analysis. Selected Papers from NWAV23 at Stanford. Stanford: CSLI Publications, pp. 69-82.

Wood, S.N., 2011. Fast stable restricted maximum likelihood and marginal likelihood estimation of semiparametric generalized linear models. Journal of the Royal Statistical Society, 73, pp.3-36. 


\begin{tabular}{|c|ccc|ccc|}
\hline \multirow{2}{*}{$\begin{array}{c}\text { MHG } \\
\text { Diphthong }\end{array}$} & \multicolumn{3}{|c|}{1982} & \multicolumn{3}{c|}{2017} \\
\cline { 2 - 7 } & Types & Tokens & DataPts & Types & Tokens & DataPts \\
\hline /i:/ & 357 & 1984 & 77,422 & 468 & 2189 & 107,184 \\
/ei/ & 391 & 3056 & 112,656 & 442 & 3525 & 151,417 \\
\hline TOTAL & 748 & 5040 & 190,078 & 910 & 5714 & 258,601 \\
\hline
\end{tabular}

Table 1. Swabian [ai] diphthong corpus based on MHG origin. 'Types' represent unique words in the transcript; 'Tokens' count the number of instances of the same word type; 'Datapts' represent the number of $\mathrm{F} 1 / \mathrm{F} 2$ frequency measurements. 


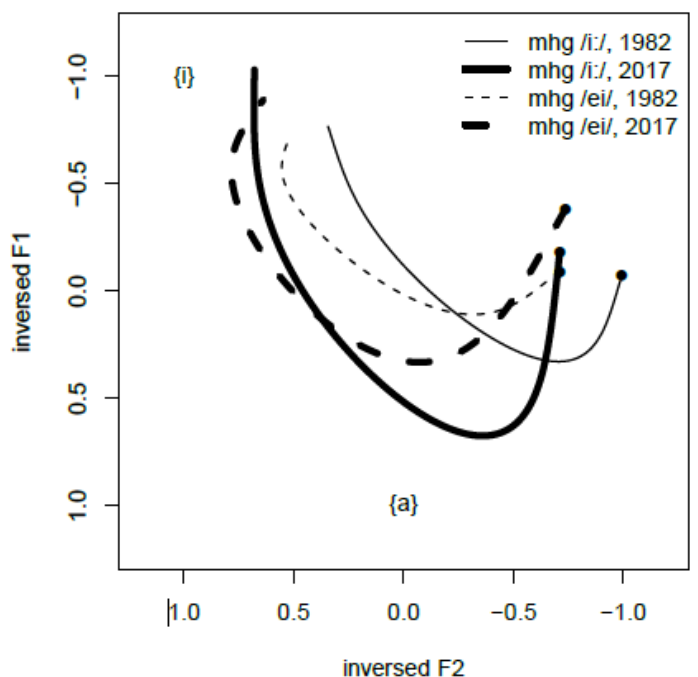

1982, Stuttgart, F1

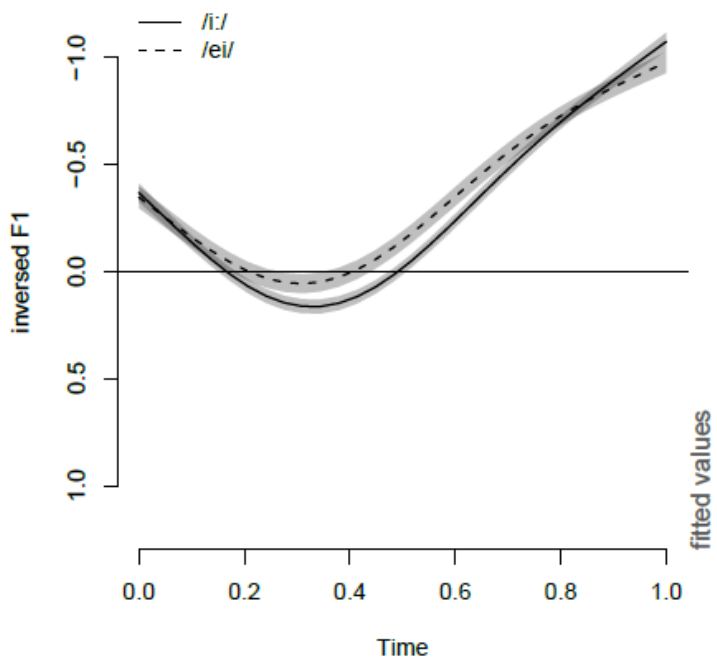

Difference between MHG /ei/ and /i:/, F1

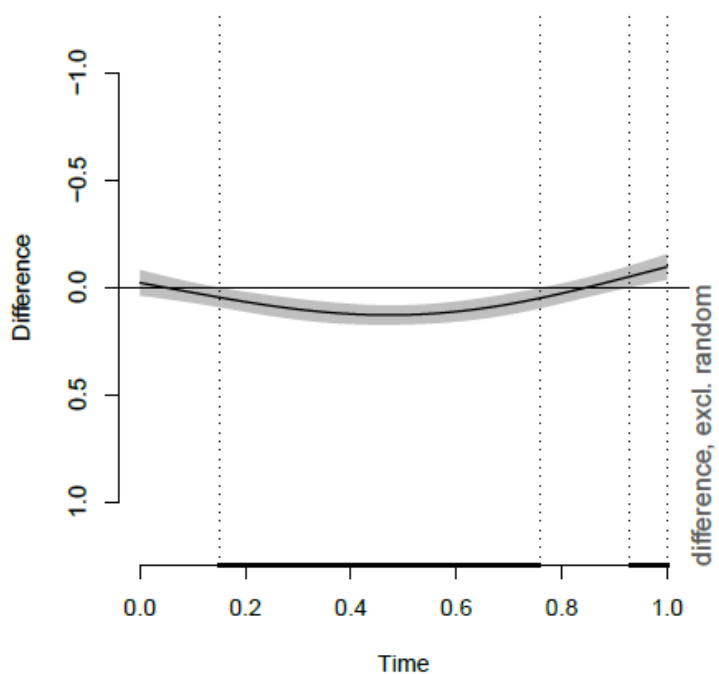

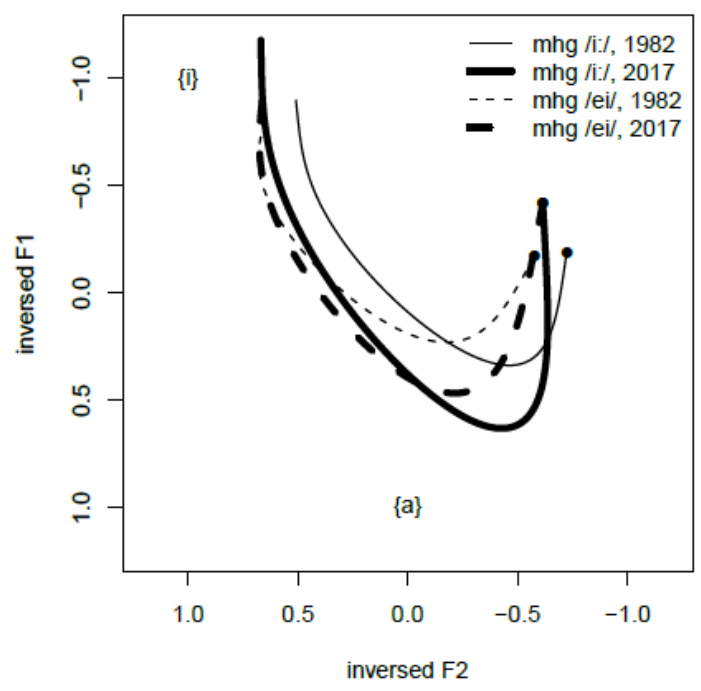

1982, Stuttgart, F2

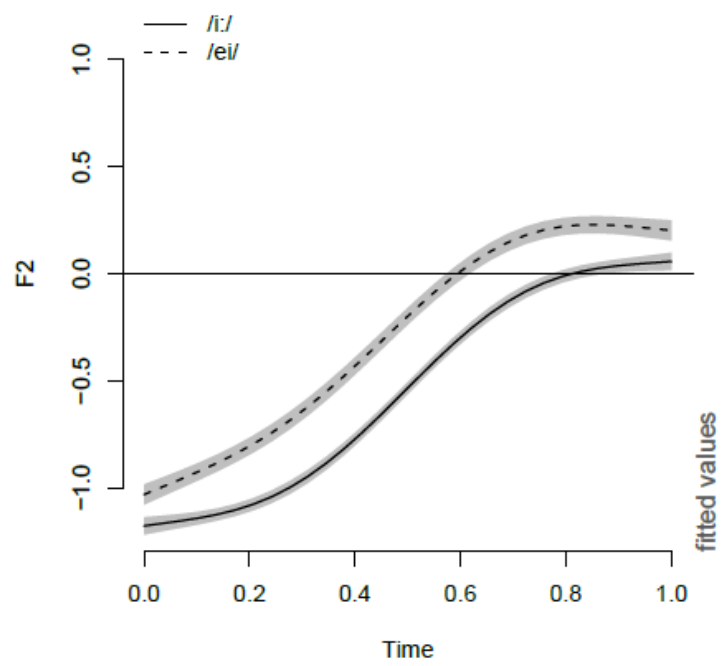

Difference between MHG /ei/ and /i:/, F2

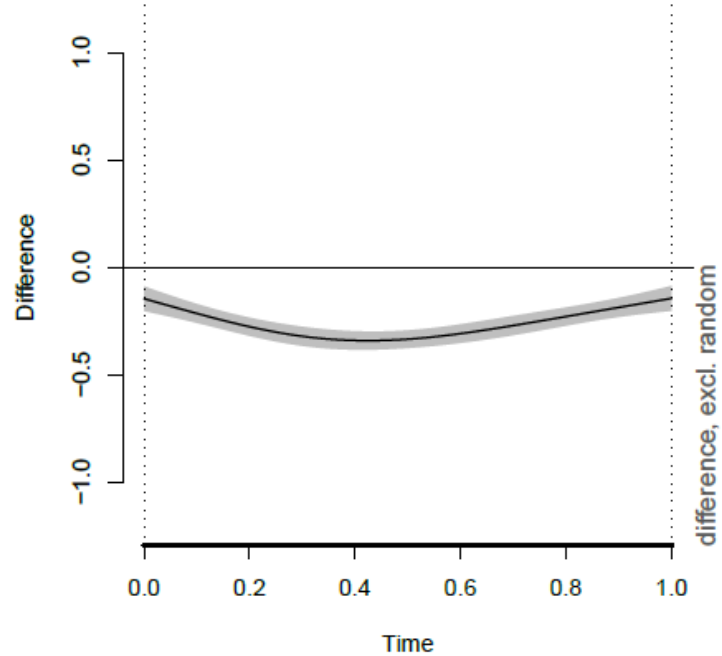

Figure 1. Example GAMM analysis. Top panel: predicted diphthong trajectories by community, year, and MHG origin. Middle panel: smooth of F1 and F2 across time for the diphthongs; Lower panel: estimated difference between the F1/F2 trajectories. 


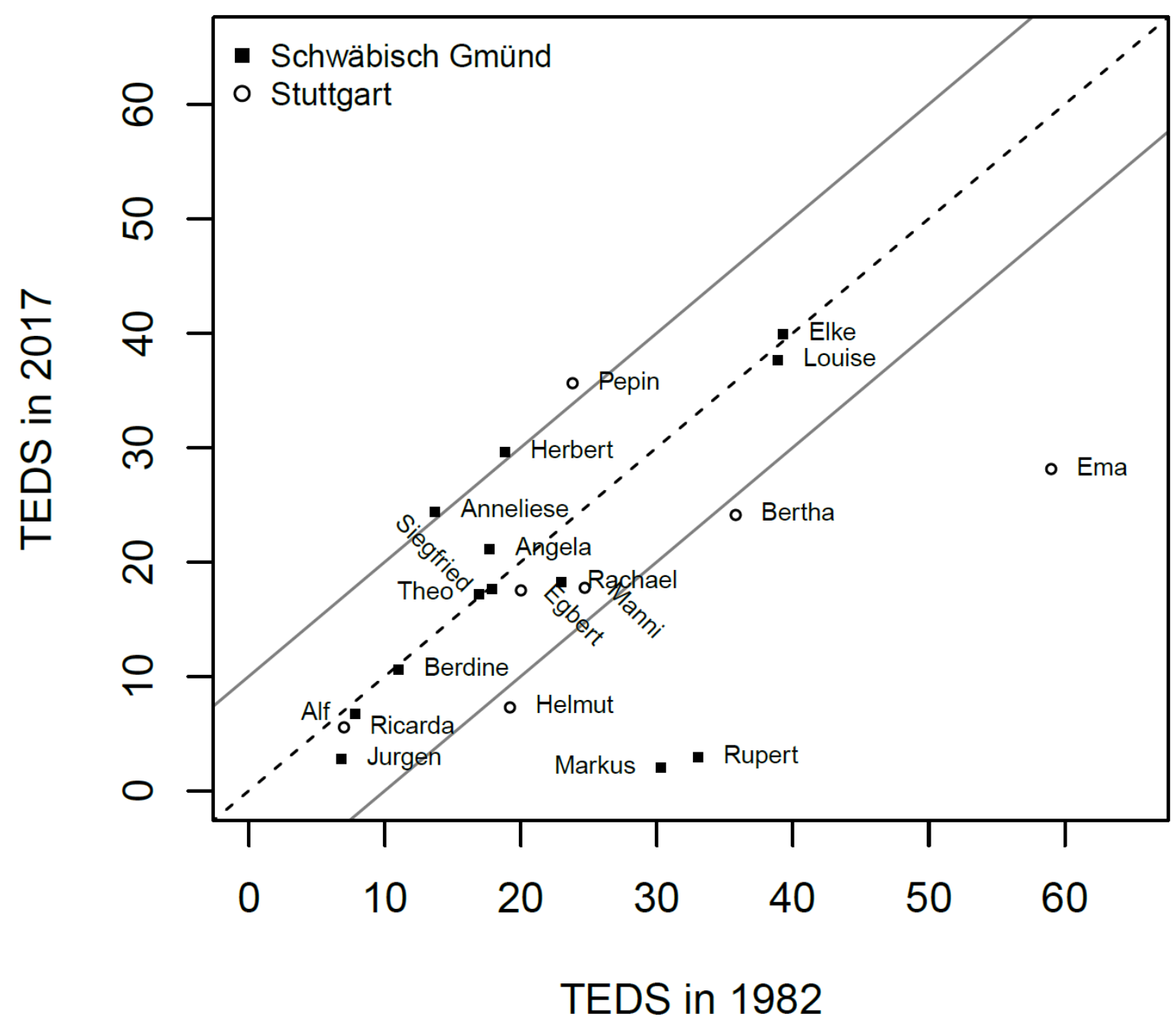

Figure 2. Total Euclidian Distance Squared (TEDS) between the F1/F2 trajectories of MHG /i:/ and /ei/ diphthongs for individual panel speakers in 1982 (x-axis) and in 2017 (y-axis). The dashed diagonal line shows equal TEDSs in 1982 and 2017, and the solid grey diagonal lines delineates TEDS greater than 10 and less than -10 . 


\begin{tabular}{|c|c|c|c|c|c|c|c|c|}
\hline & & TEDS & TEDS & TEDS & SOI & SOI & SOI & \multirow{6}{*}{$\begin{array}{l}\text { Lifespan } \\
\text { Change }\end{array}$} \\
\hline Community & Speaker & 1982 & 2017 & diff & 1982 & 2017 & diff & \\
\hline Stuttgart & Ema & 59.0 & 28.1 & -30.9 & 4.2 & 4.2 & 0.0 & \\
\hline Sch.Gmünd & Rupert & 33.0 & 2.9 & -30.1 & 4.0 & 2.6 & -1.4 & \\
\hline Sch.Gmünd & Markus & 30.3 & 2.0 & -28.3 & 4.3 & 2.8 & -1.5 & \\
\hline Stuttgart & Helmut & 19.2 & 7.3 & -11.9 & 3.3 & 2.0 & -1.3 & \\
\hline Stuttgart & Bertha & 35.8 & 24.1 & -11.7 & 3.6 & 3.3 & -0.3 & \\
\hline Stuttgart & Manni & 24.7 & 17.7 & -7.0 & 3.7 & 2.8 & -0.9 & \\
\hline Sch.Gmünd & Rachael & 23.0 & 18.2 & -4.8 & 4.4 & 4.3 & -0.1 & \\
\hline Sch.Gmünd & Jurgen & 6.8 & 2.8 & -4.0 & 3.8 & 3.3 & -0.5 & \\
\hline Stuttgart & Egbert & 20.0 & 17.5 & -2.5 & 4.0 & 3.6 & -0.4 & \\
\hline Stuttgart & Ricarda & 7.0 & 5.5 & -1.5 & 3.5 & 2.1 & -1.4 & \\
\hline Sch.Gmünd & Louise & 38.9 & 37.6 & -1.3 & 4.3 & 4.0 & -0.3 & \\
\hline Sch.Gmünd & Alf & 7.8 & 6.7 & -1.1 & 4.5 & 4.2 & -0.3 & ty \\
\hline Sch.Gmünd & Berdine & 11.0 & 10.6 & -0.4 & 3.9 & 3.3 & -0.6 & \\
\hline Sch.Gmünd & Siegfried & 17.9 & 17.6 & -0.3 & 4.2 & 4.8 & 0.6 & \\
\hline Sch.Gmünd & Theo & 16.9 & 17.2 & 0.3 & 4.0 & 3.7 & -0.3 & \\
\hline Sch.Gmünd & Elke & 39.3 & 39.9 & 0.6 & 4.2 & 4.3 & 0.1 & \\
\hline Sch.Gmünd & Angela & 17.7 & 21.1 & 3.4 & 4.5 & 4.2 & -0.3 & \\
\hline Sch.Gmünd & Anneliese & 13.7 & 24.4 & 10.7 & 3.5 & 3.6 & 0.1 & \\
\hline Sch.Gmünd & Herbert & 18.8 & 29.6 & 10.8 & 4.2 & 4.2 & 0.0 & \\
\hline Stuttgart & Pepin & 23.8 & 35.6 & 11.8 & 3.4 & 3.8 & 0.4 & \\
\hline
\end{tabular}

Table 2. Individual speakers' Total Euclidian Distance Squared (TEDS) between the F1/F2 trajectories in MHG /i:/ and /ei/ diphthong production, along with Swabian Orientation Index (SOI) scores, for the two recording years (1982 and 2017). Speakers sorted by TEDS difference between the years, revealing three typical speaker lifespan patterns: lifespan change (TEDS differences < -10; speaker stability (TEDS differences between -10 and 10); retrograde change (TEDS differences $>10$ ). 
Ema, Stuttgart

change, TEDS change $=\mathbf{- 3 0 . 9}$

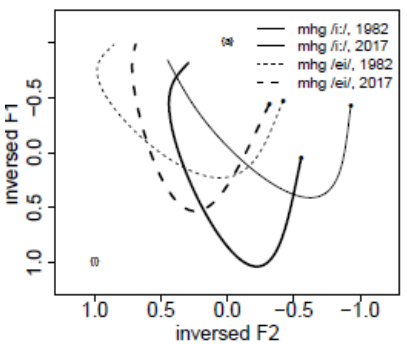

Bertha, Stuttgart change, TEDS change $=-11.7$

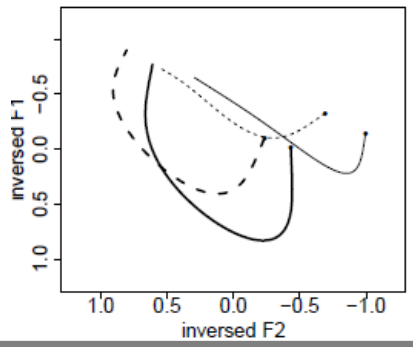

Egbert, Stuttgart stable, TEDS change $=-2.5$

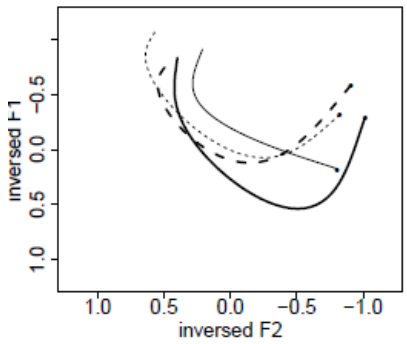

Berdine, Schwäbisch Gmünd stable, TEDS change $=-0.4$

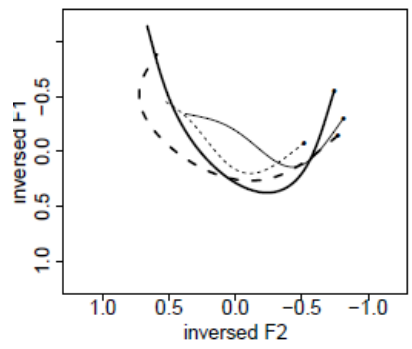

Angela, Schwäbisch Gmünd stable, TEDS change $=3.4$

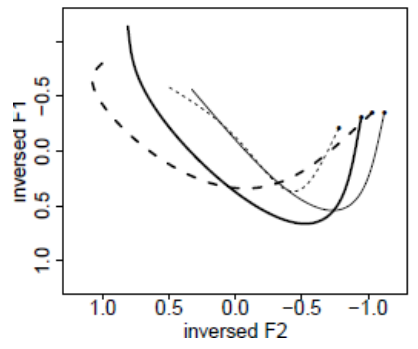

Rupert, Schwäbisch Gmünd change, TEDS change $=-\mathbf{3 0 . 1}$

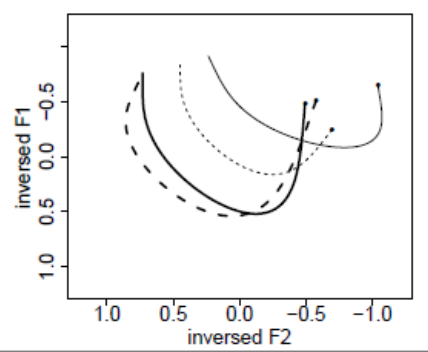

Manni, Stuttgart stable, TEDS change $=-7.0$

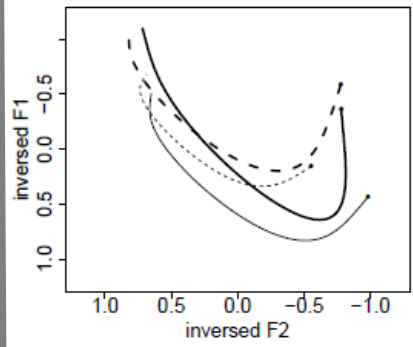

Ricarda, Stuttgart stable, TEDS change $=-1.5$

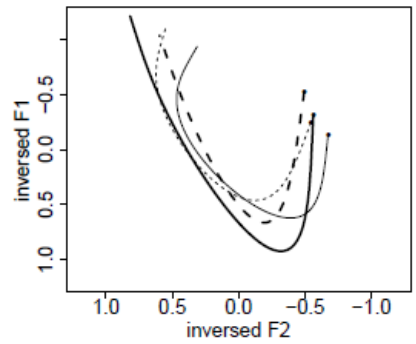

Siegfried, Schwäbisch Gmünd stable, TEDS change $=-0.3$

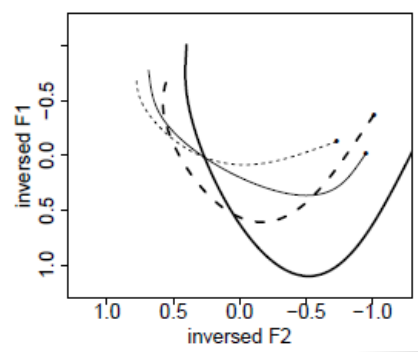

Anneliese, Schwäbisch Gmünd retrograde, TEDS change $=10.7$

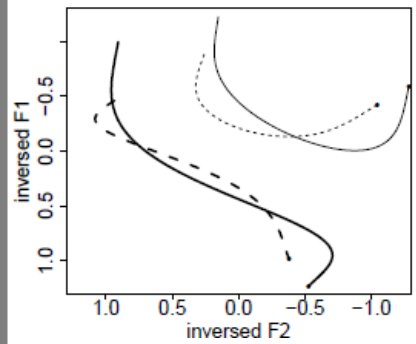

Markus, Schwäbisch Gmünd change, TEDS change $=\mathbf{- 2 8 . 3}$

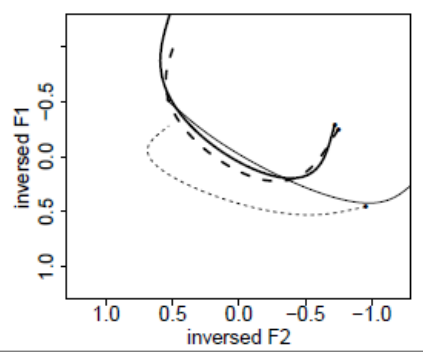

Rachael, Schwäbisch Gmünd stable, TEDS change $=-4.8$

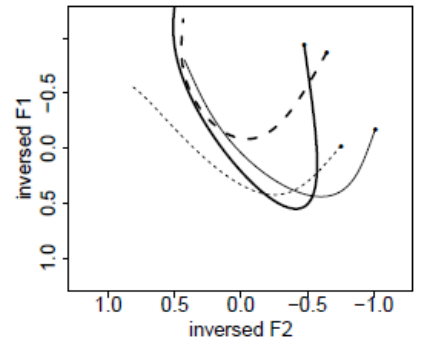

Louise, Schwäbisch Gmünd stable, TEDS change $=-1.3$

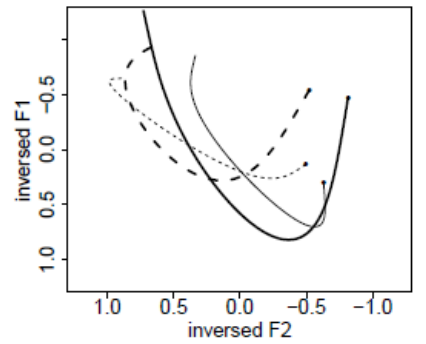

Theo, Schwäbisch Gmünd stable, TEDS change $=0.3$

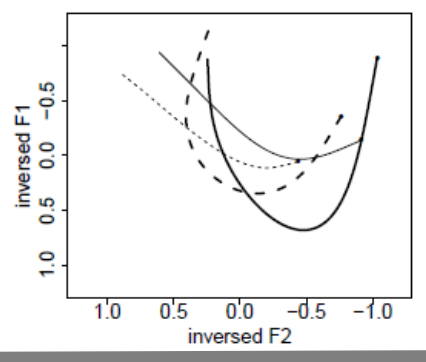

Herbert, Schwäbisch Gmünd retrograde, TEDS change $=10.8$

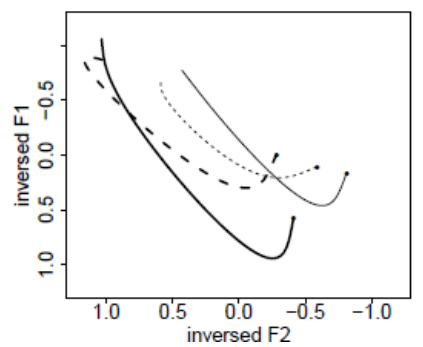

Helmut, Stuttgart

change, TEDS change $=-11.9$

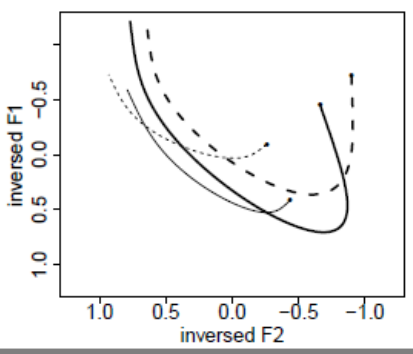

Jurgen, Schwäbisch Gmünd stable, TEDS change $=-4.0$

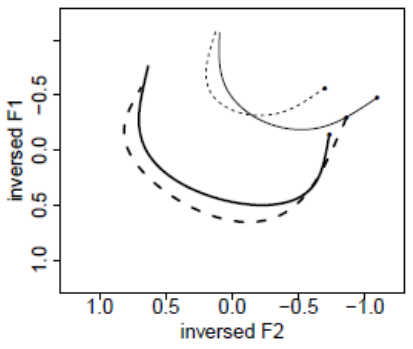

Alf, Schwäbisch Gmünd stable, TEDS change $=-1.1$

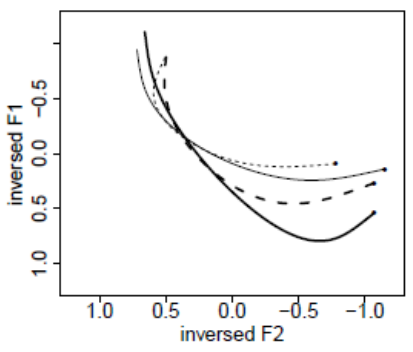

Elke, Schwäbisch Gmünd stable, TEDS change $=0.6$

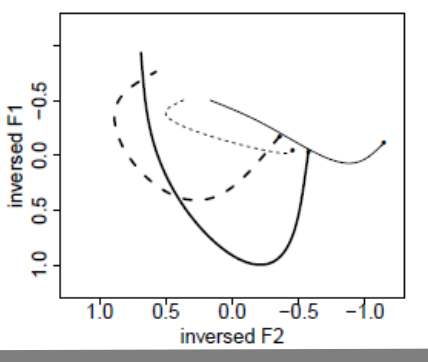

Pepin, Stuttgart retrograde, TEDS change $=11.8$

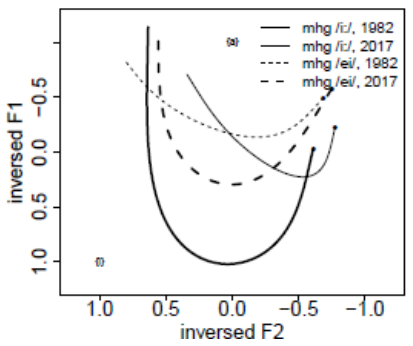

Figure 3. Individual speaker diphthong trajectories across the lifespan, sorted by Total Euclidian Distance Squared (TEDS) between the F1/F2 trajectories in MHG /i:/ and /ei/ diphthong production. 
Schwäbisch Gmünd

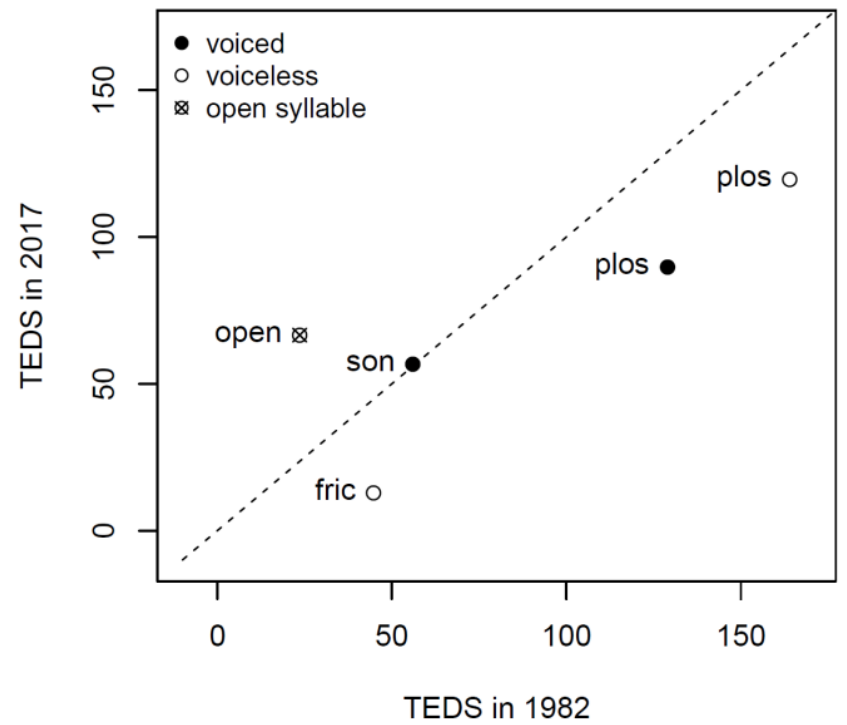

Stuttgart

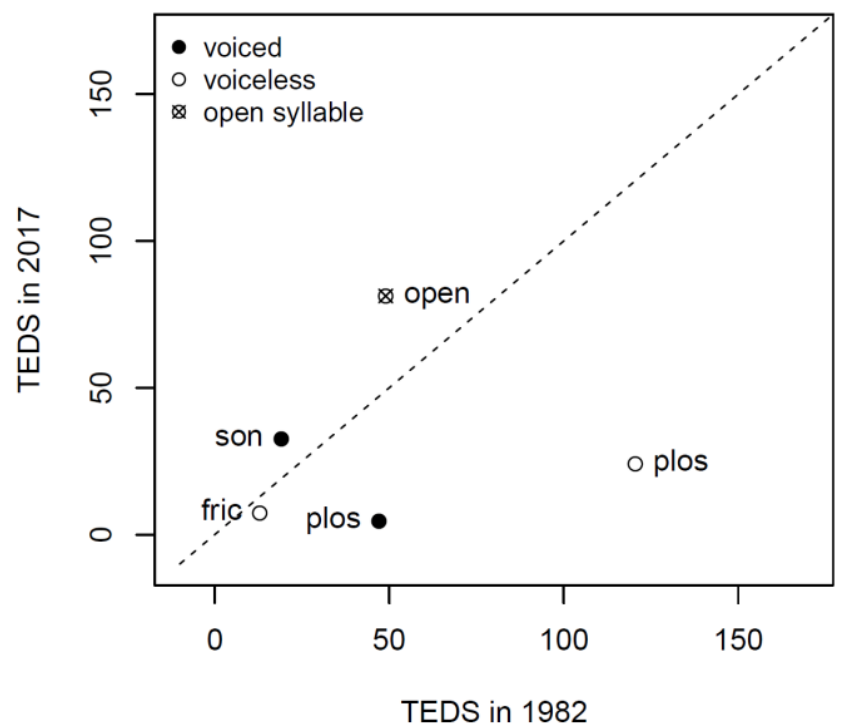

Figure 4. Total Euclidian Distance Squared (TEDS) between the F1/F2 trajectories in MHG /i:/ and /ei/ diphthong production for 1982 and 2017 based on manner and type of articulation in following environments: fric $=$ fricatives; open $=$ open syllables; plos $=$ plosives; son $=$ sonorants . The dashed diagonal line shows equal TEDSs in 1982 and 2017. 
Schwäbisch Gmünd

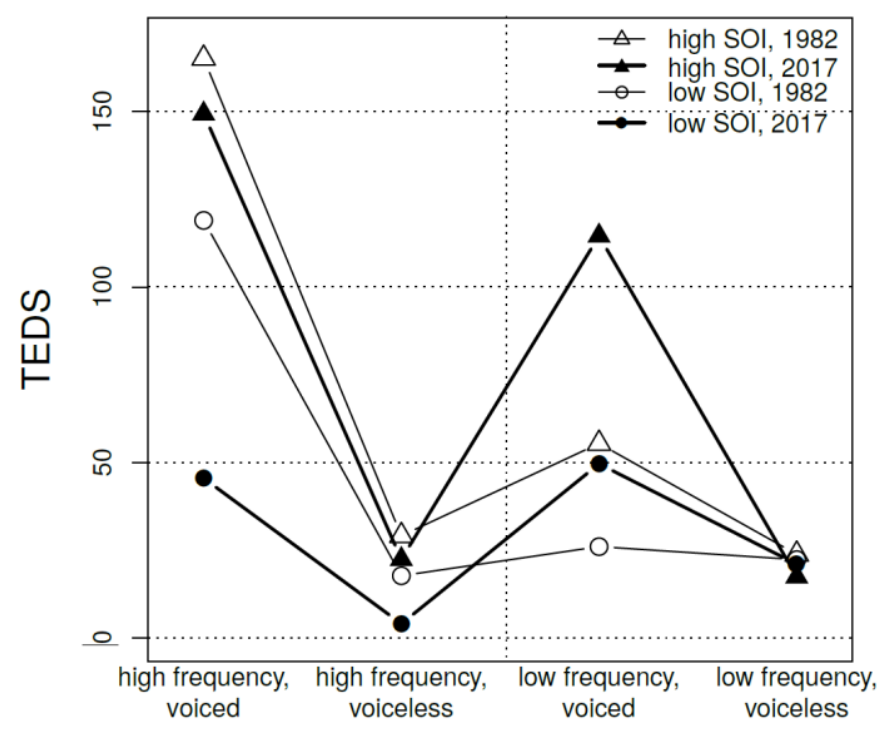

\section{Stuttgart}

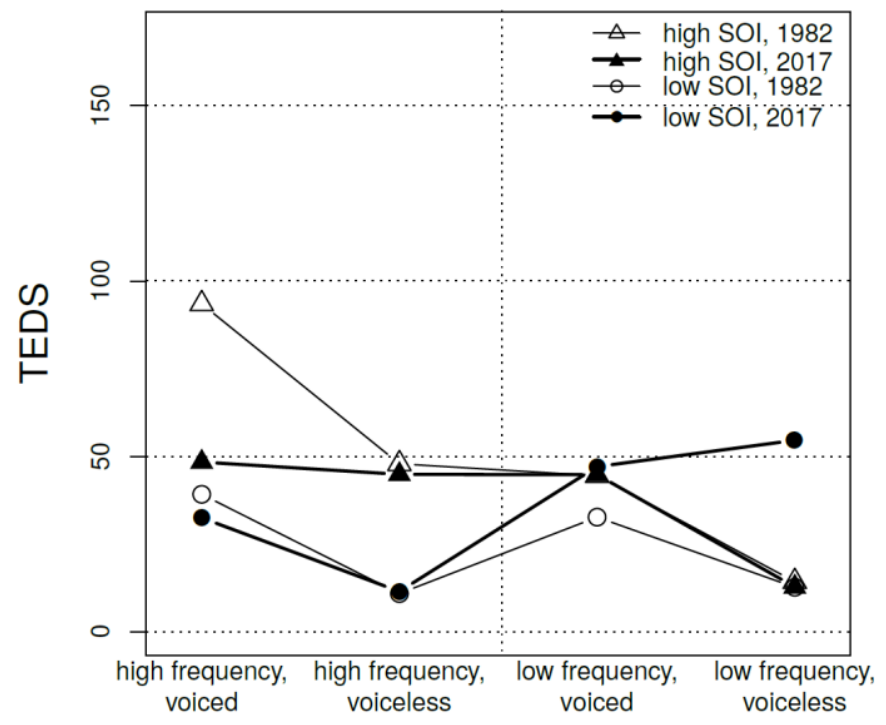

Figure 5. Total Euclidian Distance Squared (TEDS) between the F1/F2 trajectories in MHG /i:/ and /ei/ diphthong production by community, recording year, and voiced/voiceless consonants, word frequency, and Swabian orientation (SOI) (high/low SOI values determined based on a median split). 